\title{
Enhanced susceptibility of adriamycin-treated human renal cell carcinoma cells to lysis by peripheral blood lymphocytes and tumor infiltrating lymphocytes
}

\author{
X.X. WU, Y.ZENG, X.H. JIN and Y.KAKEHI \\ Department of Urology, Faculty of Medicine, Kagawa University, Kagawa, Japan
}

Received March 9, 2007; Accepted April 23, 2007

\begin{abstract}
Previous studies indicated that the anticancer agent adriamycin (ADR) could induce activation of cytotoxic $\mathrm{T}$ lymphocytes (CTL) and natural killer cells. In this study, we investigated the effect of ADR on the susceptibility of human renal cell carcinoma (RCC) cells to lysis by peripheral blood lymphocytes (PBL) and tumor infiltrating lymphocytes (TIL). Treatment of human RCC cell line ACHN and freshly derived RCC cells with ADR at $1 \mu \mathrm{g} / \mathrm{ml}$ or more for $3 \mathrm{~h}$ significantly enhanced their susceptibility to lysis by PBL $(\mathrm{P}<0.05)$. This ADR-induced enhancement of susceptibility of RCC cells to lysis by PBL was also observed when freshly derived TIL were used as effector cells $(\mathrm{P}<0.05)$. ADR up-regulated the expression of leukocyte function-associated antigen-3 (LFA-3) and intercellular adhesion molecule-1 (ICAM-1), which are critical in the binding and killing of CTL against cancer cells. Of the five fresh RCC cell cultures treated with ADR, LFA-3 was increased in all and ICAM-1 was increased in three of them, respectively $(\mathrm{P}<0.05)$. Up-regulation of LFA-3 and ICAM-1 was also observed in ACHN cells treated with two derivatives of ADR, epirubicin and pirarubicin. ADR further significantly increased the bindings of PBL to RCC cells $(\mathrm{P}<0.05)$. These findings suggest that treatment of RCC patients with low doses of ADR may sensitize the RCC cells to killing by PBL and TIL and may be a novel immunotherapeutic modality for the treatment of drug-resistant and/ or immune-resistant RCC. The inducing of LFA-3 and ICAM-1 by ADR may be involved in the enhancement of susceptibility of PBL and TIL-mediated cytolysis in human RCC cells.
\end{abstract}

Correspondence to: Dr Xiuxian Wu, Department of Urology, Faculty of Medicine, Kagawa University, 1750-1 Ikenobe, Miki-cho, Kita-gun, Kagawa 761-0793, Japan

E-mail:wuxian@med.kagawa-u.ac.jp

Key words: renal cell carcinoma, adriamycin, immunotherapy, peripheral blood lymphocytes, tumor infiltrating lymphocytes

\section{Introduction}

Many anticancer chemotherapeutic agents have cytotoxic and cytostatic effects on cancer cells, while they also have an immunosuppressive effect (1). However, it has been reported that some anticancer agents have an immunostimulatory effect (2). They can activate monocyte-mediated and lymphocytemediated cytotoxicity (3). Since the host immune defense mechanisms play an important role in fighting cancer, it is important to identify which anticancer agents are endowed with an immunostimulatory effect and which are more compatible with combined chemoimmunotherapy.

Adriamycin (ADR) is one of the most widely used antitumor drugs. In addition to its direct anti-tumor effects in vivo, ADR was found to induce the activation of cytotoxic $T$ lymphocytes (CTL), natural killer (NK) cells, and macrophages (4-6). The resistance of bladder cancer cells to killing by CTL was overcome by ADR (7). Furthermore, the susceptibility of advanced murine renal cell carcinoma (RCC) cells to CTL is enhanced by ADR in vivo (8). However, the mechanisms by which chemotherapeutic agents induce this immunopotentiation are not fully understood.

Major histocompatibility complex (MHC) antigens and adhesion molecules are critical in the recognition, binding, and killing of cytotoxic lymphocytes against cancer cells (9). Leukocyte function-associated antigen-3 (LFA-3) and intercellular adhesion molecule-1 (ICAM-1) are major adhesion molecules (10). They facilitate adhesion between target and effector cells and provide accessory signals during T-cell function, and activate CTL to proliferation, cytokine production, and cytotoxicity $(11,12)$.

In this study, we investigated the effect of ADR on the susceptibility of human RCC cells to lysis by peripheral blood lymphocytes (PBL) and tumor infiltrating lymphocytes (TIL). Furthermore, we explored molecular mechanisms involved in ADR modulating susceptibility of target cells to PBL and TIL lysis. We found that pretreatment of RCC cells with subtoxic concentrations of ADR resulted in a potentiation of anticancer activities of PBL and TIL. ADR further up-regulated LFA-3 and ICAM-1 expressions in RCC cells and increased the bindings of PBL to RCC cells. In addition, ADR sensitized RCC cells to Fas-mediated and 
TNF-related apoptosis-inducing ligand (TRAIL)-mediated cytotoxicity. These findings suggest that treatment of RCC patients with low doses of ADR may sensitize the RCC cells to killing by PBL and TIL and may be a novel immunotherapeutic modality for the treatment of drug-resistant and/ or immune-resistant RCC. The inducing of LFA-3 and ICAM-1 by ADR may be involved in the enhancement of susceptibility of PBL and TIL-mediated cytolysis in human RCC cells.

\section{Materials and methods}

Antibodies and reagents. PE-conjugated anti-MHC class I and anti-MHC class II mAbs were purchased from Ancell Corporation (Bayport, MN). FITC-conjugated anti-LFA-3 and anti-ICAM-1 mAbs were purchased from Immunotech (Marseille, France). FITC-conjugated anti-B7-1 mAb and ADR were purchased from Santa Cruz Biotechnology (Santa Cruz, CA) and Sigma (St. Louis, MO), respectively. Epirubicin (EPI) and pirarubicin (THP) were obtained from Kyowa Hakkou and Meiji Pharmaceutical (Tokyo, Japan), respectively.

Patients. Eleven peripheral blood and ten tumor tissue samples were obtained from 18 patients with RCC. The patients included 7 males and 11 females with a median age of 67.9 years, range 52-76 years. The pathological diagnosis revealed that all patients had RCC of the clear cell subtype. Their histological classification and stage according to the TNM classification was G1 $(n=7)$ and G2 $(n=11)$, and T1 $(n=5), T 2$ $(n=10)$ and T3 $(n=3)$, and N1 $(n=1)$. The patients did not receive any form of anticancer therapy during the present study. Written informed consent was obtained from all the patients.

Isolation of PBL and TIL. PBL were isolated from heparinized peripheral blood as described in detail elsewhere (7). TIL were separated from surgical specimens as described previously (13). The cell suspensions were prepared by treating finely minced tumor tissues. The various cell components were layered on discontinuous gradients consisting of $100 \%$ and 75\% Ficoll-Paque (Pharmacia Biotech AB, Uppsala, Sweden) in plastic tubes and were centrifuged at $400 \mathrm{~g}$ for $30 \mathrm{~min}$. Lymphocyte-rich mononuclear cells were collected from the $100 \%$ interface and incubated at $37^{\circ} \mathrm{C}$ for $30 \mathrm{~min}$ on plastic dishes that had been precoated with autologous serum for $15 \mathrm{~min}$ in a humidified $5 \% \mathrm{CO}_{2}$ atmosphere. Non-adherent cells were collected, cultured with medium containing IL-2 at $100 \mathrm{unit} / \mathrm{ml}$ for 2 weeks, and used as TIL.

Human RCC cell line and fresh RCC cells. Fresh RCC cells were separated from the cell suspensions enriched for tumor cells as described previously (14). The human RCC cell line ACHN and fresh RCC cells were cultured in RPMI-1640 supplemented with $10 \%$ fetal bovine serum, $25 \mathrm{mM}$ HEPES, 100 units $/ \mathrm{ml}$ penicillin, and $100 \mu \mathrm{g} / \mathrm{ml}$ streptomycin, at $37^{\circ} \mathrm{C}$ in a humidified $5 \% \mathrm{CO}_{2}$ atmosphere.

Flow cytometry. The cell surface expression of MHC class I, MHC class II, LFA-3, ICAM-1, and B7-1 on RCC cells was determined by flow cytometry. Briefly, RCC cells were seeded
Table I. Increased susceptibility of ADR-treated ACHN cells and fresh RCC cells to lysis by PBL. ${ }^{\mathrm{a}}$

$\%$ Cytotoxicity (Mean \pm SD)

\begin{tabular}{lcc} 
& & $\%$ Cytotoxicity $($ Mean $\pm \mathrm{SD})$ \\
\cline { 3 - 3 } Target cells & Concentration of & ADR $(\mu \mathrm{g} / \mathrm{ml})$ \\
& 0 & PBL \\
\hline ACHN & 1 & $9.0 \pm 6.8$ \\
& 10 & $31.6 \pm 13.4^{\mathrm{b}}$ \\
Fresh RCC & 0 & $39.5 \pm 17.6^{\mathrm{b}}$ \\
& 1 & $13.4 \pm 3.5$ \\
& 10 & $30.5 \pm 13.3^{\mathrm{b}}$ \\
\hline
\end{tabular}

${ }^{a} \mathrm{AHCN}$ cells and freshly derived RCC cells were treated with or without ADR at 1 or $10 \mu \mathrm{g} / \mathrm{ml}$ for $3 \mathrm{~h}$, washed, and used as targets for lysis by freshly isolated PBL from 7 RCC patients at an E:T of 40:1 in the MTT assay. ${ }^{\mathrm{b}} \mathrm{P}<0.05$ versus control.

in $60-\mathrm{mm}$ dishes $\left(5 \times 10^{5}\right.$ cells/dish) and cultured for $24 \mathrm{~h}$. The cells then were treated with or without ADR at $0.1-1 \mu \mathrm{g} / \mathrm{ml}$ for 3-24 h. After treatment, the cells were harvested from the substrate using $0.05 \%$ trypsin and $0.02 \%$ EDTA, washed twice in PBS containing $0.2 \%$ FBS and $0.01 \% \mathrm{NaN}_{3}$. Cells were incubated with the appropriate $\mathrm{mAbs}$ at $4^{\circ} \mathrm{C}$ for $30 \mathrm{~min}$, washed, and analyzed.

Binding activity of PBL to RCC cells. Equal numbers $\left(2 \times 10^{5}\right)$ of PBL and RCC cells were mixed in $0.2 \mathrm{ml}$ of medium in small plastic tubes and incubated for $10 \mathrm{~min}$ at $37^{\circ} \mathrm{C}$ in a humidified $5 \% \quad \mathrm{CO}_{2}$ atmosphere (15). The tubes were then centrifuged at $100 \mathrm{~g}$ for $5 \mathrm{~min}$, after which, the pellet was pipetted gently 3 times and resuspended in medium. The $\%$ binding of PBL to RCC cells was determined by counting at least 200 PBL.

Anticancer cytotoxicity assays of PBL and TIL. The microculture tetrazolium dye (MTT) assay was used to determine cytotoxic activity of lymphocytes against RCC cells (14). A $100-\mu 1$ suspension of $1 \times 10^{4}$ RCC cells was seeded into each well of 96-well flat-bottom microtiter plates. Cells were grown for $24 \mathrm{~h}$, after which, $100 \mu \mathrm{l}$ of ADR solution or medium (control) was distributed among the plates, and each plate was incubated for $3 \mathrm{~h}$ at $37^{\circ} \mathrm{C}$. Following incubation, the supernatant was aspirated, and the cells were washed 2 times with medium. PBL or TIL were added to each culture well at different effector:target ratios $(\mathrm{E}: \mathrm{T})$ in triple wells, and the plate were incubated for $21 \mathrm{~h}$ at $37^{\circ} \mathrm{C}$. Control wells containing either target cells or effector cells alone were incubated in each assay. After incubation, all non-adherent cells were removed by 4 consecutive washes with medium. After washing, $20 \mu \mathrm{l}$ of MTT working solution $(5 \mathrm{mg} / \mathrm{ml}$, Sigma) was added to each culture well followed by $180 \mu \mathrm{l}$ of medium and the cultures were incubated for an additional $4 \mathrm{~h}$ at $37^{\circ} \mathrm{C}$ in a humidified $5 \% \mathrm{CO}_{2}$ atmosphere. The culture medium was carefully aspirated from the wells and replaced with $100 \mu 1$ of isopropanol supplemented with $0.05 \mathrm{~N} \mathrm{HCl}$. Absorbance 
Table II. Increased susceptibility of ADR-treated ACHN cells and fresh RCC cells to lysis by TIL. ${ }^{\mathrm{a}}$

\begin{tabular}{lcc}
\hline & & $\%$ Cytotoxicity (Mean $\pm \mathrm{SD})$ \\
\cline { 3 - 3 } Target cells & ADR $(\mu \mathrm{g} / \mathrm{ml})$ & \multicolumn{1}{c}{ TIL } \\
\hline ACHN & 0 & $35.2 \pm 5.4$ \\
& 1 & $61.2 \pm 8.7^{\mathrm{b}}$ \\
Fresh RCC & 0 & $21.5 \pm 1.3$ \\
& 1 & $52.1 \pm 10.4^{\mathrm{b}}$ \\
\hline
\end{tabular}

${ }^{a}$ AHCN cells and freshly derived RCC cells were treated with or without ADR at $1 \mu \mathrm{g} / \mathrm{ml}$ for $3 \mathrm{~h}$, washed, and used as targets for lysis by freshly isolated TIL from 6 RCC tumors at an E:T of 20:1 in the MTT assay. ${ }^{b} \mathrm{P}<0.05$ versus control.

of each well was measured using a microplate reader (Bio-Rad, Tokyo, Japan) at $570 \mathrm{~nm}$ with a $630-\mathrm{nm}$ reference.

Direct cytotoxicity assays. The MTT assay was used to determine direct tumor cell lysis as described previously $(14,16)$. Briefly, a $100-\mu 1$ suspension of $2 \times 10^{4}$ cells was seeded into each well of 96-well flat-bottom microtiter plates. Cells were grown for $24 \mathrm{~h}$, after which, $100 \mu \mathrm{l}$ of ADR solution or medium was distributed among the plates, and each plate was incubated for $3 \mathrm{~h}$ at $37^{\circ} \mathrm{C}$. Following incubation, the supernatant was aspirated, the cells were washed 2 times with medium and incubated with or without TRAIL, Fas ligand, or anti-Fas (CH-11) for an additional $21 \mathrm{~h}$. Cytotoxicity was examined by the MTT assay.

Cell death was also evaluated by phase-contrast microscopy. Cells were seeded in a 6 -well plate $\left(3 \times 10^{5}\right.$ cells/well $)$, and were cultured for $24 \mathrm{~h}$. The cells were pretreated with or without ADR for $3 \mathrm{~h}$, washed 2 times with medium, and treated with or without TRAIL for $21 \mathrm{~h}$. Photographs of the adherent cells were taken under a phase-contrast microscope after the medium containing floating cells were removed.

Statistical analysis. All determinations were made in triplicate, and the results are presented as the mean \pm SD of three different experiments. Statistical significance was assessed by the Student's t-test. A P-value of $\leq 0.05$ was considered significant.

\section{Results}

ADR-induced immunosensitization of RCC cells to killing by $P B L$ and TIL. Table I shows the results of the effect of ADR treatment on the susceptibility of RCC cells to PBL. PBL exhibited slight cytotoxic activities against ACHN cells and freshly derived RCC cells. However, when these RCC cells were incubated with ADR $(1-10 \mu \mathrm{g} / \mathrm{ml})$ for $3 \mathrm{~h}$, the cells were significantly more sensitive to PBL than untreated RCC cells $(\mathrm{P}<0.05)$. ADR alone did not affect the number and viability of the recovered cells at concentrations between 1 and $10 \mu \mathrm{g} /$ $\mathrm{ml}$ at a 3-h time point (data not shown).

Since a previous study demonstrated that freshly separated TIL are anergic and do not kill cancer cells but their cytotoxic activity is achieved in culture with IL-2 (13), IL-2activated TIL were used as effector cells in this study. TIL displayed more remarkable cytotoxic activity against ACHN cells and freshly derived RCC cells than PBL. The treatment of RCC cells with ADR at $1 \mu \mathrm{g} / \mathrm{ml}$ for $3 \mathrm{~h}$ also sensitized the target cells to killing by TIL $(\mathrm{P}<0.05)$ (Table II). Although there were no significant differences in the ADR-augmented cytotoxic activities of the effect cells against ACHN cells or freshly derived RCC cells, the more enhanced lytic activities were observed in TIL than that observed with PBL.

Table III. Effects of ADR on the expression of LFA-3 and ICAM-1 in fresh RCC cells. ${ }^{\text {a }}$

\begin{tabular}{|c|c|c|c|}
\hline \multirow[b]{2}{*}{ Fresh RCC cells } & \multirow[b]{2}{*}{ Treatment } & \multicolumn{2}{|c|}{$\%$ Fluorescent cells $($ Mean \pm SD) } \\
\hline & & LFA-3 & ICAM-1 \\
\hline \multirow[t]{2}{*}{ Patient No. 2} & Control (Medium) & $78.4 \pm 9.4$ & $28.2 \pm 9.6$ \\
\hline & $\mathrm{ADR}$ & $96.4 \pm 2.0^{\mathrm{b}}$ & $23.5 \pm 2.9$ \\
\hline \multirow[t]{2}{*}{ Patient No. 11} & Control (Medium) & $86.0 \pm 1.1$ & $12.9 \pm 8.8$ \\
\hline & ADR & $95.9 \pm 1.6^{\mathrm{b}}$ & $14.6 \pm 6.6$ \\
\hline \multirow[t]{2}{*}{ Patient No. 12} & Control (Medium) & $62.5 \pm 3.9$ & $11.2 \pm 3.5$ \\
\hline & ADR & $91.8 \pm 2.3^{b}$ & $29.0 \pm 2.9^{\mathrm{b}}$ \\
\hline \multirow[t]{2}{*}{ Patient No. 13} & Control (Medium) & $66.6 \pm 13.6$ & $34.4 \pm 5.2$ \\
\hline & ADR & $92.6 \pm 5.8^{b}$ & $54.3 \pm 9.8^{b}$ \\
\hline \multirow[t]{2}{*}{ Patient No. 14} & Control (Medium) & $68.5 \pm 6.8$ & $16.2 \pm 4.1$ \\
\hline & ADR & $86.3 \pm 7.4^{\mathrm{b}}$ & $36.1 \pm 1.7^{\mathrm{b}}$ \\
\hline
\end{tabular}


of LFA-3 and ICAM-1. ${ }^{\mathrm{b}} \mathrm{P}<0.05$ versus control. 
$\mathbf{A}$

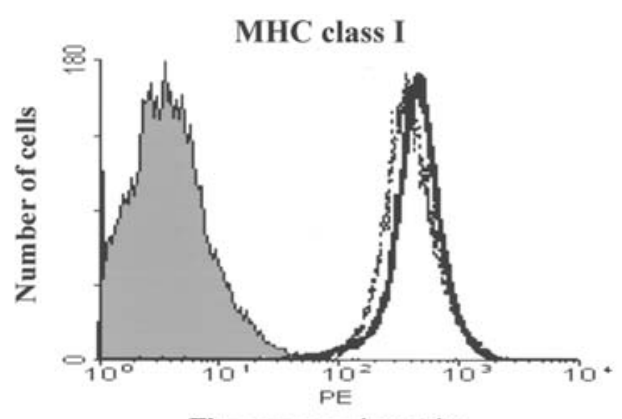

Fluorescence intensity
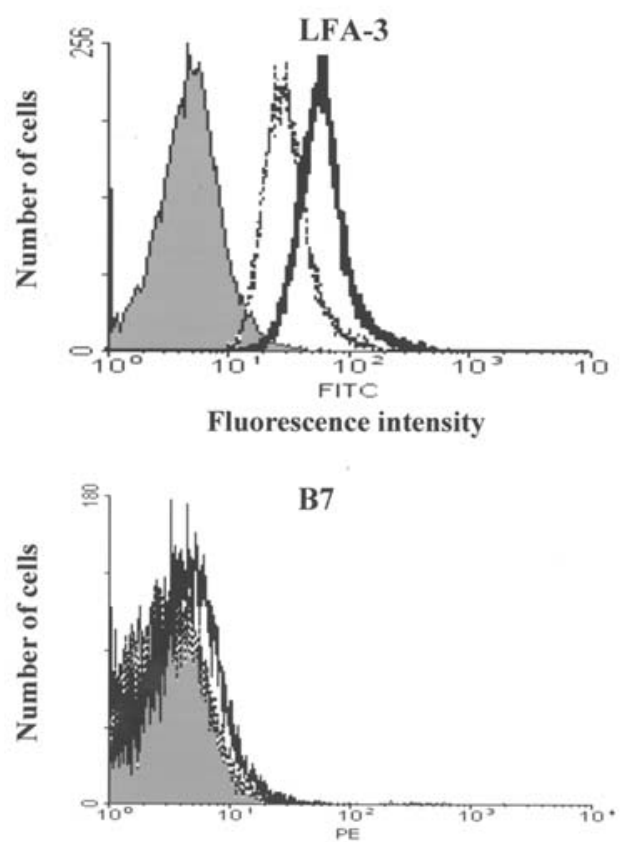

Fluorescence intensity

B

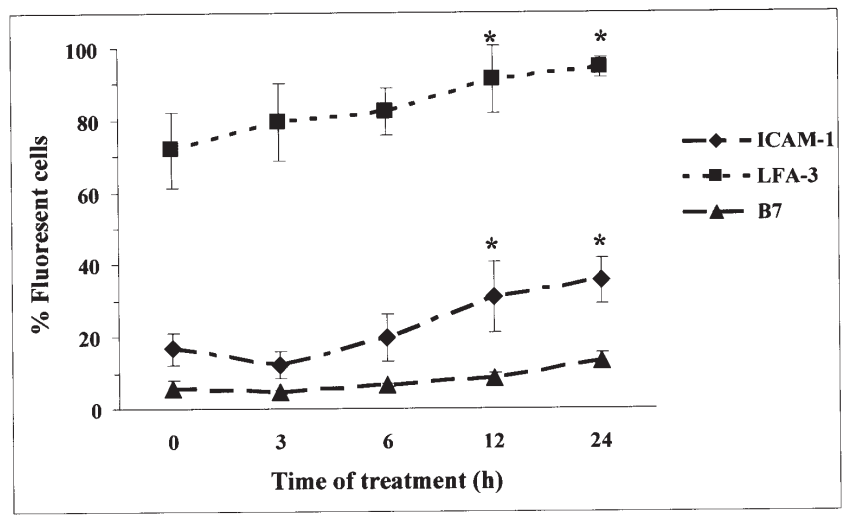

These results clearly demonstrated that pretreatment of RCC cell line or freshly derived RCC cells with subtoxic concentrations of ADR resulted in a potentiation of anticancer activities of PBL and TIL.

ADR up-regulates LFA-3 and ICAM-1 expressions. We examined by flow cytometry whether ADR regulates the cell-surface expression of MHC class I, MHC class II, LFA-3, ICAM-1, and B7. The expression of MHC class I, MHC class II, ICAM-1, LFA-3, and B7 was respectively detected in $97.7,0.58,71.9,16.7$, and $5.7 \%$ of ACHN cells. The treatment of ACHN cells with ADR 0.1-1 $\mu \mathrm{g} / \mathrm{ml}$ for 3-24 h did not affect the expression of MHC class I, MHC class II,



Fluorescence intensity

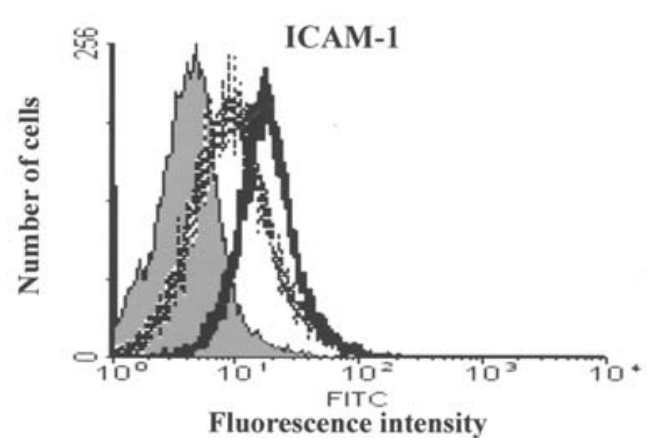

Figure 1. Effect of ADR on MHC class I, MHC class II, LFA-3, ICAM-1, and B7 expressions. ACHN cells were treated with $0.1 \mu \mathrm{g} / \mathrm{ml} \mathrm{ADR}$ for $24 \mathrm{~h}$ (A) or variable time points (B). The cells were harvested, incubated either with PE-conjugated anti-MHC class I, anti-MHC class II, FITC-conjugated anti-LFA-3, anti-ICAM-1, or anti-B7 $\mathrm{mAbs}$ for $30 \mathrm{~min}$ at $4^{\circ} \mathrm{C}$, and analyzed by flow cytometry. (A) Black dots: isotype staining; thin line histograms: MHC class I, MHC class II, LFA-3, ICAM-1, and B7 staining; and thick line histograms: the molecular staining after ADR treatment. (B) The results are presented as the mean $\pm \mathrm{SD}$ of three different experiments. ${ }^{*} \mathrm{P}<0.05$ vs. control.

or B7. However, the expression of LFA-3 and ICAM-1 was significantly augmented when the ACHN cells were exposed to ADR for $24 \mathrm{~h}$ (Fig. 1A). Furthermore, the up-regulation of LFA-3 and ICAM-1 expressions was also seen when the ADR treatment was shortened from 24 to $12 \mathrm{~h}(\mathrm{P}<0.05)$, although not at 6 or $3 \mathrm{~h}$ (Fig. 1B).

To confirm whether treatment of clinical tumor explants with ADR also up-regulates these adhesion molecular expressions, we tested them in freshly derived RCC cells from five patients. In all of them, LFA-3 expression was significantly increased after treatment with ADR $(\mathrm{P}<0.05)$. Of the five fresh RCC cell cultures treated with ADR, the expression of ICAM-1 was significantly increased in three $(\mathrm{P}<0.05)$ (Table III).

Two closely related compounds of ADR, namely EPI and THP, were also tested for their effect on the expression of LFA-3 and ICAM-1 in ACHN cells. Clearly, the up-regulation of LFA-3 and ICAM-1 was achieved with both EPI and THP treatments $(\mathrm{P}<0.05)($ Table IV).

ADR increases the bindings of PBL to RCC cells. The contact occurs between effector cells and target cells to initiate a lytic process. We then examined whether ADR facilitated the binding of PBL to RCC cells and thereby enhanced target cell lysis. PBL-RCC conjugates were prepared and counted by a phase-contrast microscope. The frequencies of PBL 
$\mathbf{A}$

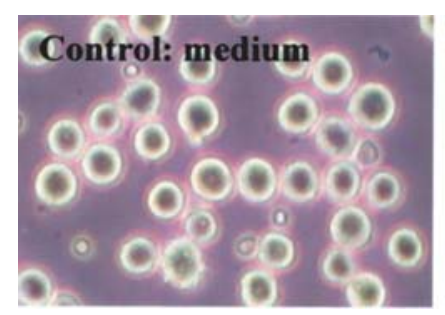

B

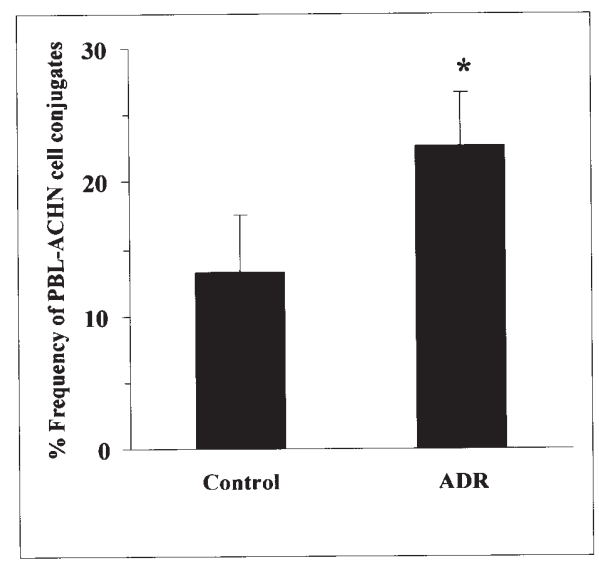

Figure 2. Effect of ADR on the formation of PBL-RCC conjugates. ACHN cells were treated with medium only or $1 \mu \mathrm{g} / \mathrm{ml}$ ADR for $24 \mathrm{~h}$, harvested, and tested for number of PBL-ACHN conjugates as described in Materials and methods. (A) The \% binding of PBL to RCC cells was observed by phase-contrast microscopy (x100). (B) PBL were derived from three patients with RCC. ${ }^{*} \mathrm{P}<0.05$ vs. control.

$\mathbf{A}$

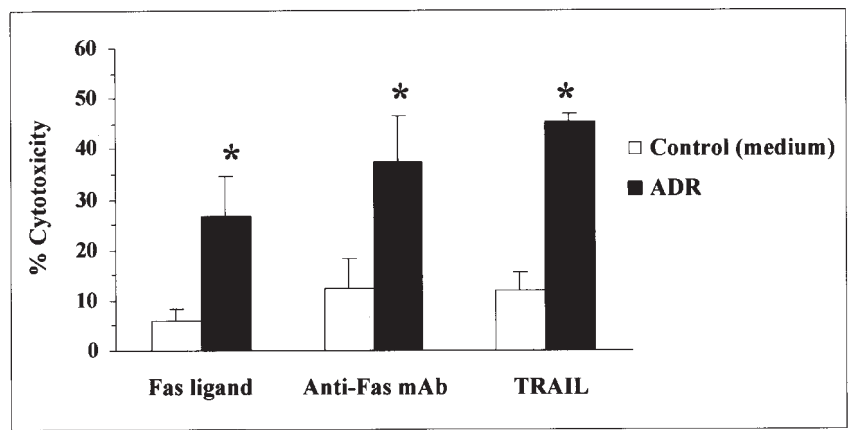

Table IV. Effects of EPI and THP on the expression of ICAM-1 and LFA-3 in ACHN cells. ${ }^{\mathrm{a}}$

\begin{tabular}{lcc}
\hline & \multicolumn{2}{c}{$\%$ Fluorescent cells (Mean \pm SD) } \\
\cline { 2 - 3 } Treatment & ICAM-1 & LFA-3 \\
\hline Control (Medium) & $6.0 \pm 0.9$ & $68.7 \pm 8.5$ \\
EPI & $24.2 \pm 4.3^{\mathrm{b}}$ & $96.1 \pm 1.6^{\mathrm{b}}$ \\
THP & $20.8 \pm 3.8^{\mathrm{b}}$ & $92.5 \pm 1.1^{\mathrm{b}}$ \\
\hline
\end{tabular}

${ }^{a} \mathrm{ACHN}$ cells were treated with or without either EPI or THP at $0.1 \mu \mathrm{g} / \mathrm{ml}$ for $24 \mathrm{~h}$, washed, and tested by flow cytometry for the expression of ICAM-1 and LFA-3. ${ }^{\mathrm{P}} \mathrm{P}<0.05$ versus control.

forming conjugates with ADR-treated ACHN cells were significantly increased compared to untreated cells $(\mathrm{P}<0.05)$ (Fig. 2). Similar results were also observed in freshly derived RCC cells (data not shown).

ADR augments Fas-and TRAIL-mediated cytotoxicity. Lymphocytes activated by cancer cells produce various kinds of cytokines which exert both cytotoxic and cytostatic activities against cancer cells (17). Thus, we examined whether ADRtreated RCC cells become more sensitive to these cytokines. When ACHN cells were incubated with ADR at 1-10 $\mu \mathrm{g} / \mathrm{ml}$ for $3 \mathrm{~h}$, the cells were not sensitive to IFN- $\alpha$, IFN- $\gamma$, or TNF- $\alpha$ (data not shown). In contrast, ACHN cells were significantly sensitive to lysis by Fas ligand, anti-Fas mAb, and TRAIL

Figure 3. ADR sensitizes RCC cells to Fas- or TRAIL-mediated cytotoxicity. (A) ACHN cells were preincubated with medium or $0.1 \mu \mathrm{g} / \mathrm{ml}$ ADR for $3 \mathrm{~h}$, washed 2 times with medium, and exposed to $1 \mu \mathrm{g} / \mathrm{ml} \mathrm{Fas}$ ligand, anti-Fas mAb, or TRAIL. Cytotoxicity was measured by the MTT assay. ${ }^{*} \mathrm{P}<0.05$ vs. control. (B) Cell death was observed by phase-contrast microscopy.
B
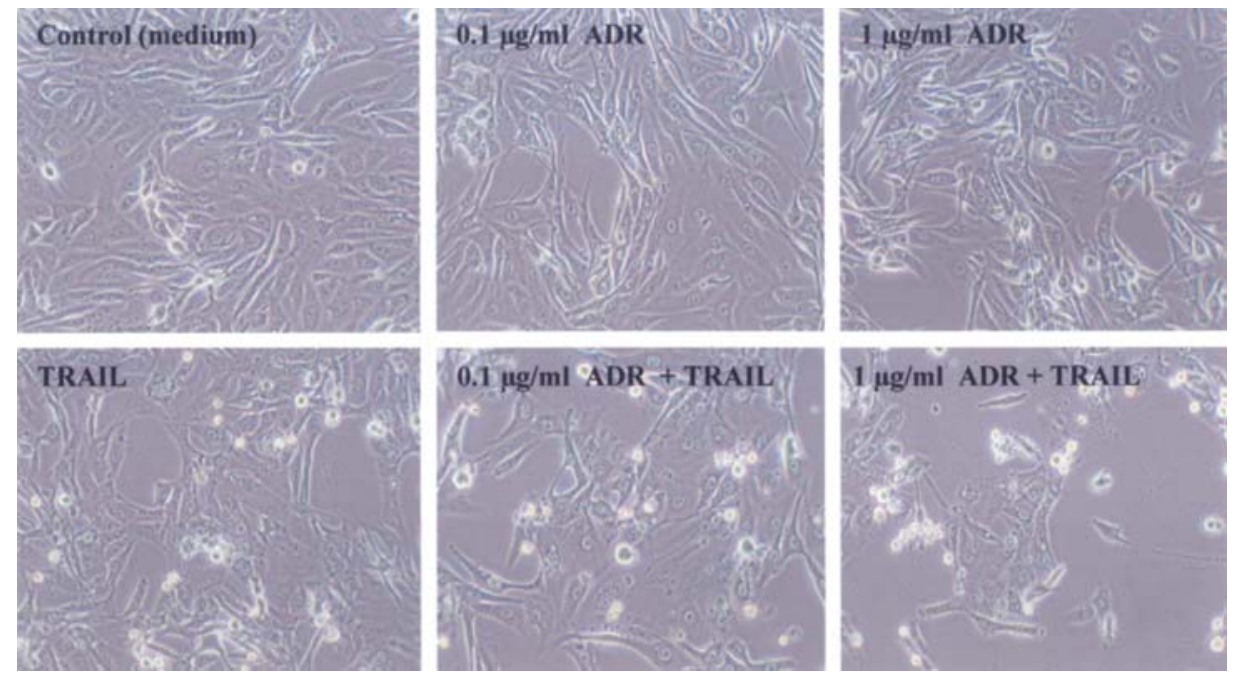
$(\mathrm{P}<0.05)$, after the cells were exposed to ADR (Fig. 3A). The sensitization of RCC cells to TRAIL-mediated cytotoxicity was confirmed by morphological examination (Fig. 3B).

\section{Discussion}

The present study showed that ADR significantly enhanced the susceptibility of RCC cells to PBL and TIL lysis. It was obtained not only in the human RCC cell line ACHN but also in freshly derived human RCC cells. ADR further upregulated the expression of LFA-3 and ICAM-1, which are critical in the binding of CTL to cancer cells. ADR also increased the binding of RCC cells to PBL. These results suggest that treatment of RCC patients with low doses of ADR may sensitize the RCC cells to killing by PBL and TIL and may be a novel immunotherapeutic modality for the treatment of drug-resistant and/or immune-resistant RCC. Furthermore, the up-regulation of expression of LFA-3 and ICAM-1 induced by ADR may play an important role in the enhanced susceptibility of RCC cells to PBL and TIL.

MHC class I, MHC class II, LFA-3, ICAM-1, and B7 are critical in the recognition, binding, and killing of CTL against tumor cells $(9,10)$. It has been reported that the sensitivity of ADR-resistant colon carcinoma cells to LAK cells depends on the level of expression of ICAM-1, LFA-3, and non-specific crossreacting antigen (18). The enhancement of LAK cell cytotoxicity is implicated in the increased expression of surface molecules including ICAM-1 and LFA-3 on the tumor cells treated with cis-diamminedichloroplatinum (II) and mitomycin-C (19). It is therefore possible that ADR might be capable of altering surface molecules of tumor cells leading to increased effector cell recognition of targets, enhanced target cell binding, and enhanced lysis. The present study showed that ADR significantly up-regulated the expression of LFA-3 and ICAM-1 on RCC cells, although there was not significant difference in the expression of MHC class I or MHC class II between ADR-treated and non-treated RCC cells. Furthermore, ADR increased the binding of RCC cells to PBL. These results imply that the up-regulation of LFA-3 and ICAM-1 may represent a novel mechanism in ADR-induced immunosensitization of RCC cells to killing by CTL.

In addition to ADR, two closely related compounds of ADR, EPI and THP, also up-regulated the expression of LFA-3 and ICAM-1 in RCC cells. Recently, animal models and clinical trials have reported that the vaccine strategies using LFA-3, ICAM-1, and B7 showed antitumor effects in mice and increased survival in patients with advanced carcinoma (20). Thus, it is warranted to study the antitumor effect of the combination of vaccine strategies using the adhesion molecules and anthracyclines.

Several anticancer chemotherapeutic agents have been demonstrated to augment the susceptibility of target cells to cellular immune attacks. Actinomycin D enhances the susceptibility of leukemia cells to lysis by NK cells (21). The susceptibility of K562 cells to PBL-mediated cytotoxicity is enhanced by cisplatin (15). These studies used primarily tumor cell lines. The present study extends these studies on druginduced sensitization of cancer cells and demonstrates the cytotoxic activity of freshly isolated PBL and TIL from the
RCC patients on ADR-treated human RCC cell line ACHN and fresh RCC cells. The pretreatment of RCC cells with clinically achievable concentrations of ADR becomes more sensitive to PBL-mediated and TIL-mediated cytotoxicity. The enhancement of sensitivity was observed not only in the human RCC cell line but also in freshly isolated RCC cells from patients. These findings suggest that ADR can act directly on the tumor cells and indirectly by augmenting host cellular immune defense mechanisms.

It is known that Fas and perforin/granzyme pathways are major mechanisms in T cell- and NK cell-mediated cytotoxicity and apoptosis against cancer cells. In addition to perforin/granzyme and Fas, TRAIL is thought to be also involved in T cell-mediated and NK cell-mediated cytotoxicity against cancer cells, which may complement the apoptotic activity of Fas and perforin/granzyme pathways (22). It is also reported that human monocytes rapidly express TRAIL, but not Fas ligand or TNF, after activation with IFN- $\gamma$ or IFN- $\alpha$ and acquire the ability to kill tumor cells (23). In this study and our previous reports, treatment of RCC cells with ADR became more sensitive to Fas- or TRAIL-mediated cytotoxicity $(14,16)$. These results suggest that the enhancement of the susceptibility of ADR-treated RCC cells to lysis by CTL appears to be due in part to their augmented susceptibility to Fas- and TRAIL-mediated cytotoxicity.

The present study demonstrates that ADR has a significant modulating effect on the susceptibility of RCC cells to lysis by PBL and TIL. These findings suggest that treatment of RCC patients with low doses of ADR may sensitize the RCC cells to killing by PBL and TIL and may be a novel immunotherapeutic modality for the treatment of drug-resistant and/ or immune-resistant RCC. Furthermore, ADR has significant up-regulating effects on the expression of LFA-3 and ICAM-1 on RCC cells and on the binding of RCC cells to PBL, indicating this ADR effect may represent a novel mechanism in the enhanced susceptibility of RCC cells to lysis by cytotoxic lymphocytes.

\section{Acknowledgements}

We thank Mr. Kouichi Yube of Research Equipment Center, Faculty of Medicine, Kagawa University, for his technical help. We are also grateful to Dr Rikiya Taoka, Dr Taniguchi Susumu, and Dr Okazoe Homare, Department of Urology, Faculty of Medicine, Kagawa University, for their assistance in the collection of blood samples. This work was supported in part by Grant-in-Aid for Scientific Research (18591757) from the Ministry of Education, Science, Culture and Sports, Japan.

\section{References}

1. Hersh EM: Immunosuppressive agents. In: Antineoplastic and Immuno-suppressive Agents I. Sartorelli AC and Johns DG (eds). Springer-Verlag, New York, pp577-617, 1974.

2. Ehrke MJ and Mihich E: Immunoregulation by cancer chemotherapeutic agents. In: The Reticuloendothelial System: A Comprehensive Treatise. Hadder JW and Szentivanyi A (eds). Vol. 8, Plenum Press, New York, pp309-347, 1985.

3. Stoychkov JM, Sclutz RM, Chirigos MA, Pavlidis NA and Goldin A: Effect of adriamycin and cyclophosphamide treatment on induction of macrophage cytotoxic function in mice. Cancer Res 39: 3014-3017, 1997. 
4. Orsini F, Pavelic Z and Mihich E: Increased primary cell mediated immunity in culture subsequent to adriamycin or daunorubicin treatment of spleen donor mice. Cancer Res 37: 1719-1726, 1997.

5. Santoni A, Riccardi C and Sorci V: Effects of adriamycin on the sensitivity of mouse natural killer cells. J Immunol 124: 2329-2335, 1980.

6. Mace K, Mayhew E and Mihich E: Alterations in murine host defense functions by Adriamycin, liposomes, or liposomeencapsulated adriamycin. Cancer Res 48: 130-136 1988.

7. Mizutani Y, Yoshida $\mathrm{O}$ and Miki T: Adriamycin-mediated potentiation of cytotoxicity against freshly isolated bladder cancer cells by autologous non-activated peripheral blood lymphocytes and tumor infiltrating lymphocytes. J Urol 162: 2170-2175, 1999

8. Gautam SC, Chikkala NF, Ganapathi R and Hamilton TA: Combination therapy with adriamycin and interleukin 2 augments immunity against murine renal cell carcinoma. Cancer Res 51: 6133-6137, 1991

9. Liu CC, Young LH and Young JD: Lymphocyte-mediated cytolysis and disease. N Engl J Med 335: 1651-1659, 1996

10. Wingren AG, Parra E, Varga M, et al: T cell activation pathways: B7, LFA-3, and ICAM-1 shape unique T cell profiles. Crit Rev Immunol 15: 235-253, 1995.

11. Omari KI and Dorovini-Zis K: Expression and function of lymphocyte function associated antigen-3 (LFA-3) at the bloodbrain barrier. Cell Mol Biol 45: 25-35, 1999.

12. Parra E, Wingren AG, Hedlund G, Kalland T and Dohlsten M: The role of B7-1 and LFA-3 in costimulation of CD8 ${ }^{+} \mathrm{T}$ cells. $\mathrm{J}$ Immunol 158: 637-642, 1997.

13. Belldegrun A, Muul LM and Rosenberg SA: Interleukin 2 expanded tumor-infiltrating lymphocytes in human renal cell cancer: isolation, characterization, and antitumor activity. Cancer Res 48: 206-214, 1998.

14. Wu XX, Mizutani Y, Kakehi Y, Yoshida O and Ogawa O: Enhancement of Fas-mediated apoptosis in renal cell carcinoma cells. Cancer Res 60: 2912-2918, 2000.
15. Mizutani Y, Bonavida B, Nio Y and Yoshida O: Enhanced susceptibility of cis-diamminedichloroplatinum-treated K562 cells to lysis by peripheral blood lymphocytes and lymphokine activated killer cells. Cancer 71: 1313-1321, 1993.

16. Wu XX, Kakehi Y, Mizutani Y, et al: Enhancement of TRAIL/ Apo2L-mediated apoptosis by adriamycin through inducing DR4 and DR5 in renal cell carcinoma cells. Int J Cancer 104: 409-417, 2003.

17. Brittenden J, Heys SD, Ross J and Eremin O: Natural killer cells and cancer. Cancer 77: 1226-1243, 1996.

18. Ishihata R, Ejiri Y, Okubo M, Ohara M and Kasukawa R: Enhancement of lymphokine-activated killer cell cytotoxicity implicated in the increased expression of surface adhesion molecules on tumor cells treated with anticancer agents. Cancer Invest 14: 427-434, 1996.

19. Rivoltini L, Cattoretti G, Arienti F, et al: The high lysability by LAK cells of colon-carcinoma cells resistant to doxorubicin is associated with a high expression of ICAM-1, LFA-3, NCA and a less-differentiated phenotype. Int J Cancer 47: 746-754, 1991.

20. Marshall JL, Gulley JL, Arlen PM, et al: A Phase I study of sequential vaccinations with fowlpox-CEA (6D)-TRICOM alone and sequentially with vaccinia-CEA (6D)-TRICOM, with and without granulocyte-macrophage colony-stimulating factor, in patients with carcinogenic antigen-expressing carcinomas. J Clin Oncol 23: 720-731, 2005.

21. Ziegler-Heitbrock HWL, Erhardt J and Riethmuller G: Treatment of fresh human leukaemia cells with actinomycin D enhances their lysability by natural killer cells. Br J Cancer 48: 507-514, 1983.

22. Kayagaki N, Yamaguchi N, Nakayama M, et al: Expression and function of TNF-related apoptosis-inducing ligand on murine activated NK cells. J Immunol 163: 1906-1913, 1999.

23. Griffith TS, Wiley SR, Kubin MZ, Sedger LM, Maliszewski CR and Fanger NA: Monocyte-mediated tumoricidal activity via the tumor necrosis factor-related cytokine, TRAIL. J Exp Med 189: 1343-1354, 1999. 